\title{
Re-Visiting Metoclopramide to Optimize Visualization with Gastrointestinal Bleeding - Mobilizing Existing Data
}

\author{
Derek J. Estes ${ }^{1}$, Shivali Berera ${ }^{2}$, Amar R. Deshpande ${ }^{3}$ and Daniel A. Sussman ${ }^{3}$ \\ ${ }^{1}$ Department of Medicine, University of Miami Leonard M. Miller School of Medicine, Miami, FL, ${ }^{2}$ Division of Gastroenterology, University of \\ Pennsylvania Perelman School of Medicine, Philadelphia, PA, ${ }^{3}$ Division of Gastroenterology, Department of Medicine, University of Miami \\ Leonard M. Miller School of Medicine, Miami, FL, USA
}

Proximal gastric visualization during endoscopy is often precluded in the event of an upper gastrointestinal bleed (UGIB) due to retained blood. ${ }^{1}$ Prokinetic agents might improve visualization by increasing the tone and amplitude of gastric contractions. ${ }^{2}$

Despite its common use, there remains no published data on the efficacy of using metoclopramide prior to endoscopy in cases of acute UGIB. The 2010 consensus recommendation against the routine use of promotility agents in nonvariceal UGIB referenced a meta-analysis in which prokinetic administration reduced the need for repeat endoscopy without additional clinical benefits. ${ }^{3,4}$ This observation was driven by the results of two randomized control trials (RCTs) using erythromycin, with conclusions regarding metoclopramide limited to the findings of two unpublished abstracts. ${ }^{5,6}$ Since 2010, a meta-analysis of eight RCTs has shown that pre-endoscopic erythromycin improved visualization, reduced the need for repeat endoscopy, and decreased the length of hospital stay. ${ }^{7}$ Conversely, a placebo-controlled RCT of 23 patients presented in an abstract form showed no effect of metoclopramide on visualization. $^{8,9}$

Given the lack of published data on the use of metoclopramide, we re-examined our institution's data on endoscopic

Received: February 7, 2019 Revised: March 12, 2019

Accepted: March 12, 2019

Correspondence: Derek J. Estes

Department of Medicine, University of Miami Leonard M. Miller School of Medicine, P.O. Box 016960 R-59, Miami, FL 33101, USA

Tel: +1-321-431-1233, Fax: +1-305-243-4920, E-mail: destes@med.miami.edu ORCID: https://orcid.org/0000-0002-2794-7857

(c) This is an Open Access article distributed under the terms of the Creative Commons Attribution Non-Commercial License (http://creativecommons.org/ licenses/by-nc/3.0) which permits unrestricted non-commercial use, distribution, and reproduction in any medium, provided the original work is properly cited. visualization in patients with UGIB presented in an abstract form. This RCT randomized 52 consecutive patients with overt UGIB (including from portal hypertension) who had not received gastric lavage or motility-affecting medications to receive either metoclopramide 30-120 minutes prior to endoscopy or no medication. The investigators used Avgerinos scores ${ }^{10,11}$ to assess the visual quality of the endoscopy. Previous reports showed a non-significant trend toward improved proximal gastric visualization, with no effects on the duration of endoscopy, transfusion requirement, need for repeat endoscopy, or length of hospital stay. We have subsequently stratified these results based on the etiology for bleeding. Our subgroup analysis revealed that metoclopramide improves fundal visualization in patients with non-ulcer causes of UGIB (mean Avgerinos score: 1.67 , standard deviation $[S D]=0.52$ ) compared to not using metoclopramide in patients with non-ulcer causes of UGIB (mean Avgerinos score: 0.40, SD=0.55). These findings require further validation with a larger sample size but raise the hypothesis that metoclopramide may improve visualization in the subgroup of patients in whom portal hypertension is the etiology for UGIB.

Conflicts of Interest

The authors have no financial conflicts of interest.

\section{Author Contributions}

Conceptualization: Derek J. Estes, Shivali Berera, Amar R. Deshpande, Daniel A. Sussman

Data curation: DJE, SB, ARD, DAS

Formal analysis: DJE, SB, ARD, DAS

Investigation: DJE, SB, ARD, DAS

Methodology: SB, ARD, DAS

Project administration: SB, ARD, DAS

Software: DJE, SB, ARD, DAS 
Supervision: SB, ARD, DAS

Validation: DJE, SB, ARD, DAS

Writing-original draft: DJE, SB, ARD, DAS

Writing-review\&editing: DJE, SB, ARD, DAS

\section{REFERENCES}

1. Stollman NH, Putcha RV, Neustater BR, Tagle M, Raskin JB, Rogers AI. The uncleared fundal pool in acute upper gastrointestinal bleeding: implications and outcomes. Gastrointest Endosc 1997;46:324-327.

2. Georgiadis GT, Markantonis-Kyroudis S, Triantafillidis JK. Prokinetic agents: current aspects with focus on cisapride. Ann Gastroenterol 2000;13:269-289.

3. Barkun AN, Bardou M, Kuipers EJ, et al. International consensus recommendations on the management of patients with nonvariceal upper gastrointestinal bleeding. Ann Intern Med 2010;152:101-113.

4. Barkun AN, Bardou M, Martel M, Gralnek IM, Sung JJ. Prokinetics in acute upper GI bleeding: a meta-analysis. Gastrointest Endosc 2010;72:1138-1145

5. Habashi SL, Lambiase LR, Kottoor R. Prokinetics infusion prior to endoscopy for acute upper gastrointestinal bleeding: a randomized, con- trolled, double-blind and placebo-controlled trial. Am J Gastroenterol 2007;102:S526.

6. Sussman DA, Deshpande AR, Parra JL, Ribeiro AC. Intravenous metoclopramide to increase mucosal visualization during endoscopy in patients with acute upper gastrointestinal bleeding: a randomized, controlled study. Gastrointest Endosc 2008;67:AB247.

7. Rahman R, Nguyen DL, Sohail U, et al. Pre-endoscopic erythromycin administration in upper gastrointestinal bleeding: an updated meta-analysis and systematic review. Ann Gastroenterol 2016;29:312-317.

8. Daram S, Johnson W, Abrasley C, Siddaiah N, Garretson R. A double blind randomized study to evaluate the use of metoclopramide before endoscopy for upper gastrointestinal bleeding. Am J Gastroenterol 2010;105(Suppl 1):S508.

9. Daram SR, Garretson R. Erythromycin is preferable to metoclopramide as a prokinetic in acute upper GI bleeding. Gastrointest Endosc 2011;74:234; author reply 234-235.

10. Avgerinos A, Nevens F, Raptis S, Fevery J. Early administration of somatostatin and efficacy of sclerotherapy in acute oesophageal variceal bleeds: the European acute bleeding oesophageal variceal episodes (ABOVE) randomised trial. Lancet 1997;350:1495-1499.

11. Frossard JL, Spahr L, Queneau PE, et al. Erythromycin intravenous bolus infusion in acute upper gastrointestinal bleeding: a randomized, controlled, double-blind trial. Gastroenterology 2002;123:17-23. 